\title{
Molecular determinants of improved cathepsin B inhibition by new cystatins obtained by DNA shuffling
}

Napoleão F Valadares ${ }^{1 \dagger}$, Márcia Dellamano ${ }^{2 \dagger}$, Andrea Soares-Costa ${ }^{2}$, Flávio Henrique-Silva ${ }^{2 *}$, Richard C Garratt ${ }^{1 *}$

\begin{abstract}
Background: Cystatins are inhibitors of cysteine proteases. The majority are only weak inhibitors of human cathepsin B, which has been associated with cancer, Alzheimer's disease and arthritis.

Results: Starting from the sequences of oryzacystatin-1 and canecystatin-1, a shuffling library was designed and a hybrid clone obtained, which presented higher inhibitory activity towards cathepsin B. This clone presented two unanticipated point mutations as well as an N-terminal deletion. Reversing each point mutation independently or both simultaneously abolishes the inhibitory activity towards cathepsin B. Homology modeling together with experimental studies of the reverse mutants revealed the likely molecular determinants of the improved inhibitory activity to be related to decreased protein stability.

Conclusion: A combination of experimental approaches including gene shuffling, enzyme assays and reverse mutation allied to molecular modeling has shed light upon the unexpected inhibitory properties of certain cystatin mutants against Cathepsin B. We conclude that mutations disrupting the hydrophobic core of phytocystatins increase the flexibility of the N-terminus, leading to an increase in inhibitory activity. Such mutations need not affect the inhibitory site directly but may be observed distant from it and manifest their effects via an uncoupling of its three components as a result of increased protein flexibility.
\end{abstract}

\section{Background}

The human cathepsins B and L are cysteine proteases of the papain subfamily, which primarily function as endopeptidases within endolysosomal compartments. Causal roles for cathepsins in cancer have been demonstrated by pharmacological and genetic techniques [1], and different mechanisms were shown to increase the expression of cathepsins B and L in tumours [2]. Furthermore, given the involvement of cathepsin $B$ in neurobiological functions and neurodegenerative disease [3], tumor progression and arthritis [2], a better understanding of its

\footnotetext{
* Correspondence: dfhs@power.ufscar.br; richard@if.sc.usp.br

+ Contributed equally

${ }^{1}$ Center for Structural Molecular Biotechnology, Department of Physics and Informatics, Physics Institute of São Carlos, University of São Paulo, Av. Trabalhador são-carlense 400, 13560-970, São Carlos-SP, Brazil

¿2aboratory of Molecular Biology, Department of Genetic and Evolution, Federal University of São Carlos, Rodovia Washington Luis km 235, CEP

13565-905, São Carlos-SP, Brazil

Full list of author information is available at the end of the article
}

function at the molecular level and of the mechanisms of cathepsin inhibition is desirable.

Cystatins are a group of cysteine protease inhibitors that have been identified in vertebrates, invertebrates, and plants. Plant cystatins, also known as phytocystatins, are proteins characterized by the absence of disulfide bonds and putative glycosilation sites, which cluster in a major evolutionary tree branch of the cystatin superfamily of proteins [4]. In plants, phytocystatins regulate endogenous proteolytic activities, also having a role in improving defense mechanisms against insects and pathogens [5]. Recent studies have characterized sugarcane cystatins [6-8], proteins that have a role in resistance to pathogenic attacks towards sugarcane (Saccharum officinarum), a crop extensively cultivated in Brazil due to its economic implications as a renewable energy source [9].

The best studied phytocystatin is oryzacystatin-1 from rice, whose fold can be described as a five-stranded antiparallel $\beta$-sheet wrapped around a central helix [10], being stabilized by a hydrophobic cluster formed 
between the two which contains a specific LARFAV-like conserved sequence present only in phytocystatins [4]. Cystatins use three structural elements to interact and inhibit cysteine proteases, two loops together with the $\mathrm{N}$-terminal region. Both loops physically interact with the active site of the cysteine protease, the first through its QXVXG motif (residues Q53 to G57 in oryzacystain-1) and the second via residues P83 and W84. The $\mathrm{N}$-terminal region does not directly interact with the active site, but makes extensive contacts with the protease, playing an important role in the binding process [10-12].

Here, we describe the use of DNA shuffling to create a new hybrid cystatin with improved cathepsin B inhibitory activity, obtained through the recombination of canecystatin- 1 and oryzacystatin- 1 . The activity and physicochemical properties of three other mutants obtained through the reversion of point mutations observed in this hybrid, as well an N-terminally deleted version of oryzacystatin, were also determined. Analysis of molecular models of these recombinant proteins was used to explain the molecular determinants of their activities.

\section{Methods}

\section{DNA shuffling library construction}

The method used involves the fragmentation of genes with similar DNA sequences using DNase I to generate a pool of random DNA fragments. These fragments were reassembled into a full-length gene by repeated cycles of annealing in the presence of DNA polymerase. The fragments prime on each other based on sequence homology, and recombination occurs when fragments from one gene anneal to fragments from the other, causing a template switch.

\section{Gene Selection}

The choice of specific genes encoding counterpart cysteine protease inhibitors in sugarcane (CaneCPI-1, [GenBank:AY119689]) and rice (oryzacystatin I, [GenBank:U54702]) was based on the similarity of their DNA sequences $(56 \%)$.

\section{Substrate Preparation}

The principle of DNA shuffling is recombining distinct genes that present high similarity in their DNA sequence. In our case, the selected genes CaneCPI-1 and OC-I were used in the construction of the shuffling library. The substrates used for the shuffling reactions were PCR products obtained from the amplification of the CaneCPI- 1 and OC-I genes using the pET28aCaneCPI-1 [6] and pET28OC-I [13] plasmids respectively, as templates. For CaneCPI-1 amplification by PCR the following primer sequences were employed: CaneCPI-1F (5' TCGAAGGTCGTCATATGATGGCCGAGGCAC $3^{\prime}$ ) and T7 terminator (5' TAGTTATTGCTCAGC GGTGG 3'). In the case of the OC-I gene the primer T7 promoter (5' TAATACGACTCACTATAGGG 3') together with the $\mathrm{T} 7$ terminator primer were used. Free primers from the PCR product were removed by Wizard PCR (Promega).

\section{DNAse I Digestion}

About $4 \mu \mathrm{g}$ of amplification product (DNA substrate) were digested with 0.15 unit of DNAse I $(10 \mathrm{U} / \mu \mathrm{l})$ in $100 \mu \mathrm{l}$ of buffer containing $50 \mathrm{mM}$ Tris- $\mathrm{HCl}, \mathrm{pH}$ 7.4, $1 \mathrm{mM} \mathrm{MnCl}_{2}$, for 10-20 min at room temperature. Fragments of 40-120 bp were recovered from $2 \%$ low melting point agarose gels by electrophoresis using the gel Kit QIAEX II Agarose Gel Extraction (QIAGEN) and ethanol precipitated.

\section{PCR without primer}

The recovered fragments of 40-120 bp obtained from DNase I digestion were used in the reaction of recombination. The first extension was performed using $5 \mu \mathrm{l}$ of each purified fragment and re-suspended in $20 \mu \mathrm{l}$ of PCR mixture containing $0.2 \mathrm{mM}$ each dNTPs, $1.5 \mathrm{mM}$ $\mathrm{MgCl} 2,0.1 \mu \mathrm{l} \mathrm{Taq} \mathrm{DNA} \mathrm{Polymerase}(5 \mathrm{U} / \mu \mathrm{l}), 0.1 \mu \mathrm{l} P f u$ Turbo DNA Polymerase $(2.5 \mathrm{U} / \mu \mathrm{l})$ and $2 \mu \mathrm{l}$ Taq buffer $10 \times$. This solution was submitted to a round of extension of 40 cycles at $95^{\circ} \mathrm{C} / 30 \mathrm{sec}, 50^{\circ} \mathrm{C} / 30 \mathrm{sec}, 72^{\circ} \mathrm{C} / 2$ $\min +2 \mathrm{sec} /$ cycle.

\section{PCR with Primers}

$8 \mu \mathrm{l}$ of recombination product obtained from PCR without primers were used in $100 \mu \mathrm{l}$ of PCR mixture with $0.2 \mathrm{mM}$ dNTPs, $10 \mu \mathrm{l}$ of amplification buffer (10x), $3 \mu \mathrm{l}$ $\mathrm{MgCl}_{2}(50 \mathrm{mM}), 2 \mu \mathrm{l}$ first OC-I forward primer $(10 \mathrm{pmol} / \mu \mathrm{l})$ and CaneCPI-1 reverse primer $(10 \mathrm{pmol} / \mu \mathrm{l})$, $2.5 \mathrm{U}$ of Taq DNA Polymerase. The conditions for amplification were: $1 \times\left[94^{\circ} \mathrm{C} / 1 \mathrm{~min}\right], 35 \times\left[94^{\circ} \mathrm{C} / 1 \mathrm{~min}, 47^{\circ} \mathrm{C} / 1\right.$ min and $\left.72^{\circ} \mathrm{C} / 1.5 \mathrm{~min}\right]$ and $1 \times\left[72^{\circ} \mathrm{C} / 5 \mathrm{~min}\right]$. The amplification product was submitted to analysis by agarose gel electrophoresis and amplified DNA was purified from the gel using the QIAEX II gel extraction kit (QIAGEN).

\section{Cloning and Analysis}

The plasmid pET28a was cut with Eco RI and Nde I and dephosphorylated with shrimp alkaline phosphatase (SAP) in $5 \mu$ l buffer containing $200 \mathrm{mM}$ Tris $\mathrm{pH} 8.0$ and $100 \mathrm{mM} \mathrm{MgCl}$; $1 \mu \mathrm{l} \mathrm{SAP}(1 \mathrm{U} / \mu \mathrm{l})$ and water to $50 \mu \mathrm{l}$ for an incubation of 1 hour at $37^{\circ} \mathrm{C}$. The inactivation of SAP was performed at $70^{\circ} \mathrm{C}$ for $20 \mathrm{~min}$. This solution was precipitated with ethanol and re-suspended in water to a final volume of $30 \mu \mathrm{l}$. The products of final amplification 
were digested with the restriction enzymes Eco RI and Nde I and ligated in the dephosphorylated pET28a plasmid. The ligation reaction was used to transform $E$. coli Rosetta (DE3), for expression of the hybrid proteins.

About 2000 clones were sequenced by the dideoxy method [14] using an ABI Prism 377 (Applied Biosystems). The sequences obtained were then analyzed using BLAST alignments and the software Multalin http:// bioinfo.genotoul.fr/multalin/multalin.html in order to find a clone resulting from recombination. Based on the recombinants obtained several clones were selected and submitted to expression analysis and subsequent inhibitory activity assays.

\section{Site-directed mutagenesis}

Site-directed mutagenesis was performed using the Gene Tailor $^{\mathrm{m}}$ Site Directed Mutagenesis System (Invitrogen). The pET28a encoding the mutant A10 gene was used as template DNA for the construction of the reverse mutant 1 (T30I) and mutant 2 (Q97L). The DNA corresponding to mutant 2 was used as a template for the construction of reverse mutant- 3 (the double mutant) using the mutant- 1 primers to allow for both mutations. The primer sequences were as follows: mutant-1 forward, 5'GACCTCGAGGCCATCGAGCTCGCGCGC-3'; mutant1 reverse, 5'-CTTGTCCTTGCTGAGCTCCGG-3'; mutant-2 forward, 5'-AACTTCAAGCAGCTGCAGAGCTTCAG-3'; mutant-2 reverse, 5'-CCACACCCT CTTGAAGTTCGTC-3'. PCR products were analyzed on agarose gels to confirm the presence of a product of the correct molecular weight and all plasmids were sequenced.

The recombinant cystatins were expressed in E. coli Rosetta (DE3) carrying the appropriate pET28a vector, and purified as previously described $[6,8]$.

\section{Expression of recombinant cystatins and mutants}

Two clones of the shuffling library were selected for this study. One of these, here termed OC-I N $\Delta$, was a pure oryzacystatin clone which presented a seven-residue $\mathrm{N}$ terminal deletion. The second was a hybrid clone containing two mutations besides the $\mathrm{N}$-terminal deletion (clone A10). These clones were selected for expression and inhibition assays together with OC-1, CaneCPI-1, CaneCPI-4, and the mutant 1,2 , and 3 . The corresponding constructs were used to transform competent strains of E. coli Rosetta (DE3) with calcium chloride. The transformed cells were cultivated at $37^{\circ} \mathrm{C}$ under agitation in selective medium containing kanamycin $(25 \mathrm{mg} / \mathrm{mL})$ until they reached an optical density (O.D.) of 0.6, at $600 \mathrm{~nm}$, when protein expression was induced by the addition of IPTG to a final concentration of $0.4 \mathrm{mM}$. Aliquots were taken for up to $4 \mathrm{~h}$ (at 1 hour intervals) after induction and the cell extract was analyzed on SDS-PAGE 15\% [15]. After induction, the cells were collected, centrifuged, and subjected to a solubility test. To this end, the cells were suspended in suspension buffer containing $10 \mathrm{mM}$ Tris- $\mathrm{HCl}, 100 \mathrm{mM} \mathrm{NaCl}, 50 \mathrm{mM}$ $\mathrm{NaH}_{2} \mathrm{PO}_{4}, \mathrm{pH} 8.0$ and subjected to lyses by sonication five times for $1 \mathrm{~min}$ at $30 \mathrm{~s}$ intervals. The lysed cells were centrifuged at $13,000 \mathrm{~g}$ and $4^{\circ} \mathrm{C}$ for $10 \mathrm{~min}$, and the supernatant and precipitate analyzed on SDS-PAGE $15 \%$ [15].

\section{Purification of the recombinant proteins}

The fraction containing the soluble proteins was purified from the supernatant using a nickel affinity column, Ni-NTA superflow (Qiagen). The column was equilibrated and washed with two column volumes of suspension buffer and after sample application the proteins were eluted with increasing imidazol concentrations (10, $25,50,75,100$, and $250 \mathrm{mM}$ ). The purified proteins were analyzed on SDS-PAGE $15 \%$. The fractions containing the purified proteins were dialyzed using MWCO: 3 membranes (Spectrum Laboratories) and the concentrations determined by Bradford's method [16].

\section{Enzyme inhibition activity}

The inhibitory activity of the recombinant cystatins was measured against human cathepsins B and L (Calbiochem) using the fluorogenic substrate Z-Phe-Arg-MCA (Calbiochem) as previously described [8]. Briefly, human cathepsins $B$ and $\mathrm{L}(0.3 \mathrm{nM})$ were individually incubated for $5 \mathrm{~min}$ at $37^{\circ} \mathrm{C}$ with different inhibitors CaneCPI-1, OC-I, OC-I N $\Delta$, A10, mutant 1, mutant 2 and mutant 3 in a buffer containing $100 \mathrm{mM}$ sodium acetate $\mathrm{pH} 5.5$, $2.5 \mathrm{mM}$ DTT. The concentration range of each inhibitor is presented in Additional file 1. The substrate Z-PheArg-MCA $(0.01 \mathrm{mM})$ was added and the residual hydrolytic activity was monitored using a Hitachi F-2500 spectrofluorometer $\left(\lambda_{\text {ex }}=380 \mathrm{~nm}\right.$ and $\left.\lambda_{\text {em }}=460 \mathrm{~nm}\right)$. All experiments were carried out in triplicate and the results used to determine $K_{\mathrm{i}(\mathrm{app})}$ by non linear regression using the GraFit program [17]. The equilibrium inhibition constant $\left(K_{\mathrm{i}}\right)$ of the enzyme inhibitor complex was subsequently calculated using Morrison's procedure $[18,19]$.

\section{Molecular Modeling}

The amino acid sequences of oryzacystatin-1 and human stefin B were retrieved from Swiss-Prot (accession numbers [Swiss-Prot:P09229] and [Swiss-Prot:P04080], respectively) and the three-dimensional structures were obtained from the protein databank (1EQK and 1STF, respectively). The sequences were aligned using CLUSTALX http://www.clustal.org/download/current/ and the result manually adjusted based on structural superposition. The sequences of the cystatins were then aligned to this template. 
Comparative molecular models corresponding to each of these alignments were obtained using the program MODELLER 9v8 [20]. A series of different models were generated and their quality evaluated by the MODELLER pseudo-energy term and its DOPE score [21]. The models were also subjected to independent evaluation by the programs VERIFY 3D [22] and WHATIF [23], and a representative model for structural analysis was selected.

\section{Results and Discussion}

A total of two thousand clones were sequenced from the shuffling library. Amino acid sequence analyses were made in order to find a hybrid formed by the CaneCPI-I and OC-I proteins. It was expected that the DNA encoding two distinct but similar proteins would form a heteroduplex hybrid, but in practice most of the analyzed clones in the library were homoduplex. Approximately $50 \%$ and $25 \%$ of clones were identical to OC-I and CaneCPI-1, respectively. A further $20 \%$ corresponded to OC-I with the N-terminal deletion (OC-I $\mathrm{N} \Delta$ ) and the remaining $5 \%$ were shuffled, truncated or presented point mutations. From among the many clones OC-I N $\Delta$ and A10, the latter belonging to the remaining $5 \%$, were selected to be of potential interest.

Expression and purification assays for OC-I, CaneCPI-1, CaneCPI-4, OC-I N $\Delta$, A10, mutant 1 , mutant 2 and mutant 3 was performed and analyzed in a Coomassie blue stained SDS-PAGE (Figure 1). This analysis revealed the presence of the His-tagged proteins of expected sizes for the induced clones, the insoluble and soluble fractions, and the purified recombinant protein. Most of the recombinant proteins were in their soluble form and could be purified directly by affinity chromatography on a nickel column using $250 \mathrm{mM}$ imidazole. Even CaneCPI-4, A10 and mutant 1 , which presented high amounts of protein in the insoluble fraction, could be purified from the supernatants. The amounts of pure recombinant proteins obtained after a single step of purification were sufficient for performing activity tests.

The cysteine peptidases cathepsin L and B were assayed in the presence of the recombinant cystatins. Their inhibitory activity was assessed in a fluorometric assay using Z-Phe-Arg-MCA as substrate for which cathepsin $\mathrm{L}$ and B present $K_{\mathrm{M}}$ values of $2 \mu \mathrm{M}$ and 23.4 $\mu \mathrm{M}$, respectively [24]. The residual hydrolytic activity of the enzyme was measured after pre-incubation for 5 minutes with the inhibitors at different concentrations. The resulting $K_{\mathrm{i}}$ values are shown in Table 1.

Two clones in particular (OC-I N $\Delta$ and A10) presented interesting profiles in terms of enzyme inhibition. The majority of cystatins, such as oryzacystatin-1 (from which OC-I N $\Delta$ was derived) and canecystatin-1, bind more tightly to cathepsin $\mathrm{L}$ than to cathepsin $\mathrm{B}$, and typically show at least one order of magnitude difference in terms of $K_{\mathrm{i}}$. OC-I N $\Delta$, on the other hand, presented no activity towards Cathepsin B whilst still retaining moderate activity towards cathepsin L. A completely different profile was shown by A10 which presented comparable inhibition of both enzymes due to an increased activity towards Cathepsin B $\left(K_{\mathrm{i}}=11.21 \mathrm{nM}\right.$, see Table 1$)$.

Four differences can be noted between A10 and the original canecystatin-1 from which it is largely derived. Firstly, the N-terminal region of A10 comes from oryzacystatin-1 and not canecystatin-1, a result of the gene shuffling process itself. Secondly, this region has suffered a 7 amino acid deletion (Figure 2). Finally, A10 has acquired two unexpected point mutations affecting hydrophobic residues of the protein core, I30T at the beginning of the $\alpha$-helix and L97Q in strand $\beta 5$ (residue numbers follow those of canecystatin-1 throughout the text unless otherwise stated, see Figure 2).

Table 1 also shows data on enzyme inhibition by mutants in which these specific peculiarities of A10 were individually dissected. A deletion mutant of oryzacystatin-1 which reproduces the effect of the loss of seven residues towards the $\mathrm{N}$-terminus of A10, retained nanomolar activity towards cathepsin L, but lost all of its activity towards Cathepsin B. This is consistent with the current model for cathepsin B inhibition by cystatins in which initial binding of the $\mathrm{N}$-terminal region precedes a conformational change to the occluding loop $[25,26]$. Changes to this region are known to significantly affect inhibitory activity towards cathepsin B, and the residues lost as a consequence of the deletion have been identified as important for protease binding [12]. It is therefore not entirely unexpected that the two reverse mutants of A10 (T30I and Q97L), which also present the 7-residue deletion, were also unable to significantly inhibit Cathepsin B. On the other hand both retained their ability to inhibit Cathepsin $\mathrm{L}$ at the nMolar level, indicative of correct folding. What is more surprising is the ability of A10 itself to inhibit cathepsin B at all. The accumulation of the two mutations together is somehow able to overcome the deleterious effect of the $\mathrm{N}$-terminal deletion and to turn A10 into a nMolar inhibitor of cathepsin B.

\subsection{Sequences and molecular homology models analysis}

A homology model for the canecystatin-1 structure shows that, unlike a similar model for clone A10, it preserves the hydrophobic core seen in oryzacystatin-1 [10]. This is located at the interface between the fivestranded anti-parallel $\beta$-sheet and the single $\alpha$-helix (Figure 3). In the $\beta$-sheet of canecystatin-1, the residues involved in this interface are M47, L48, F50, L53, V56 (in strand $\beta 2$ ), F68, V70, V72 (strand $\beta 3$ ), Y82, A84, V86 (strand $\beta 4$ ) and L97, F100 (strand $\beta 5$ ). The clone A10 presents a glutamine residue instead of a leucine in 


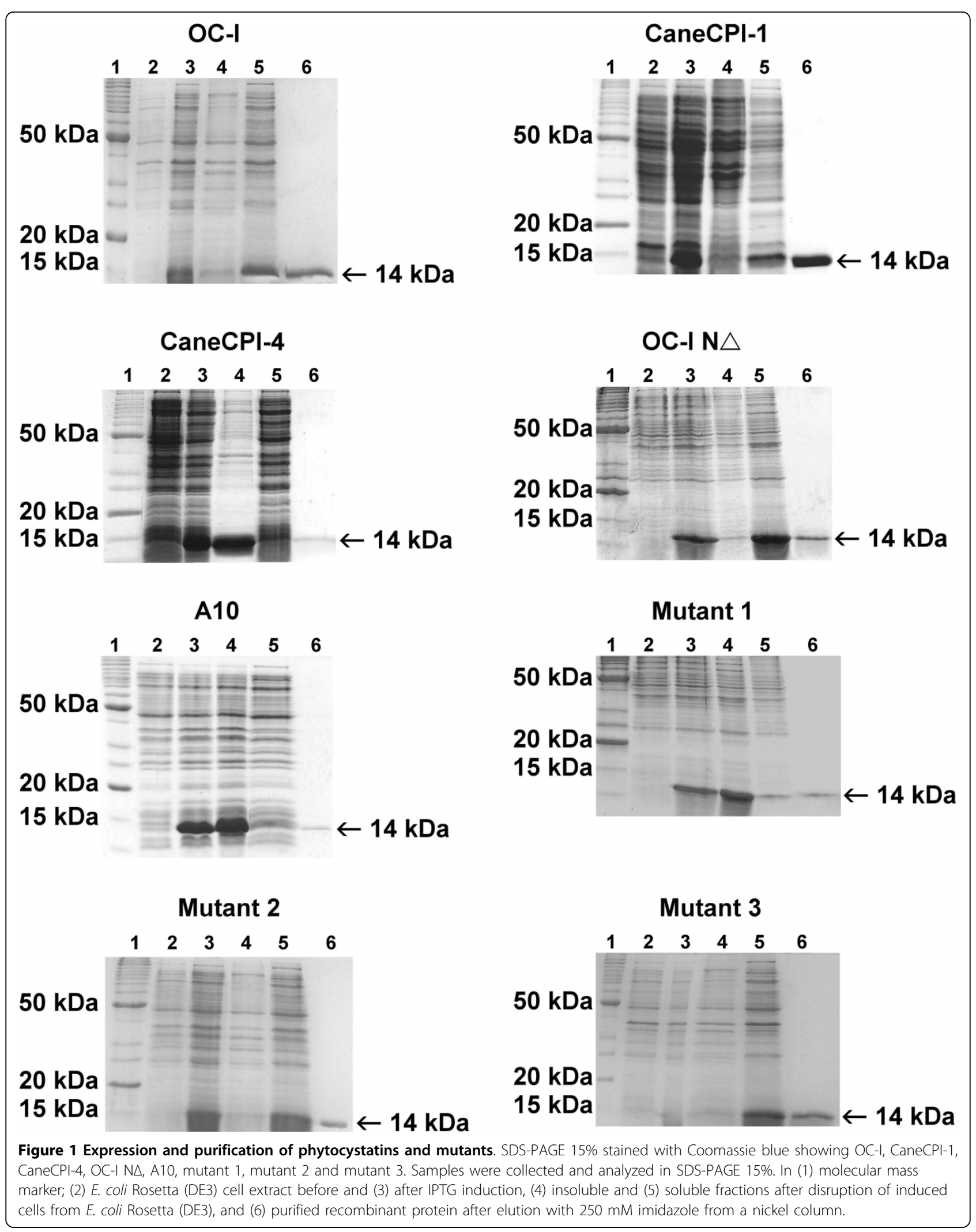


Table 1 Inhibition of cathepsins B and L by cystatins ${ }^{a}$

\begin{tabular}{|c|c|c|}
\hline \multirow[t]{2}{*}{ Cystatin } & \multicolumn{2}{|c|}{$K_{\mathrm{i}}$} \\
\hline & Cathepsin B & Cathepsin L \\
\hline Oryzacystatin-1 & $78.5 \mathrm{nM}$ & $0.73 \mathrm{nM}$ \\
\hline Canecystatin-1 & $87.6 \mathrm{nM}$ & $0.10 \mathrm{nM}$ \\
\hline Canecystatin- $4^{\mathrm{b}}$ & $0.58 \mathrm{nM}$ & $0.0035 \mathrm{nM}$ \\
\hline 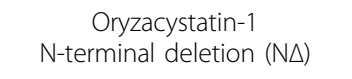 & $\mathrm{NI}$ & $5.66 \mathrm{nM}$ \\
\hline Clone A10 & $11.2 \mathrm{nM}$ & $1.63 \mathrm{nM}$ \\
\hline Reverse Mutant 1 (T30I) & $\mathrm{NI}$ & $1.93 \mathrm{nM}$ \\
\hline Reverse Mutant 2 (Q97L) & $\mathrm{NI}$ & $11.7 \mathrm{nM}$ \\
\hline Reverse Mutant 3 (T30I, Q97L) & $\mathrm{NI}$ & $12.5 \mathrm{nM}$ \\
\hline
\end{tabular}

${ }^{a} \mathrm{NI}$ indicates no inhibitory activity observed at the highest concentration of the inhibitor employed.

${ }^{\mathrm{b}}$ data previously published [8].

the position 97 (Figure 3). Close to the $\mathrm{N}$-terminus of the helix there is a small strand $(\beta 1)$ which interacts with $\beta 2$ via both main chain hydrogen-bonds as well as hydrophobic contacts involving A21 and V56, the latter on strand $\beta 2$. The helix residues most obviously involved in the hydrophobic core are I30 and the residues of the conserved LARFAV sequence. The remarkable conservation of this motif among phytocystatins has been emphasized previously, but the authors were unable to attribute to it a specific functional role [27]. We propose that the role of this motif is to provide ideal complementarity to the hydrophobic residues in the $\beta$-sheet of the phytocystatins, essential for stabilizing the tertiary structure.

The three active site segments of phytocystatins which directly interact with the binding pocket of the enzyme have been proposed based on the complex formed between stefin $B$ and papain $[10,11]$. The first interacting loop corresponds to canecystatin-1 residues 59-63, presenting the highly conserved sequence QVVAG, which is identical in oryzacystatin-1 and A10. The second binding loop includes V90 and W91 (P 83 and W84 in oryzacystatin-1) and the third interaction site is formed by the N-terminal region.

These three regions form the classical interaction surface between cystatins and cysteine proteinases. However, Cathepsin B, different from Cathepsin L and most other cysteine proteinases, possesses a large insertion (the occluding loop) which covers part of the binding pocket thus impeding the simultaneous entry of all three elements of the inhibitor's active site. The observed binding of some cystatins to Cathepsin B is explained by a two-step mechanism in which the initial binding of the $\mathrm{N}$-terminal region leads to subsequent displacement of the occluding loop generating an effective binding mode $[25,26]$. Furthermore, recent studies employing single mutations at positively selected amino acid sites confirm the functional importance of the $\mathrm{N}$-terminal region of phytocystatins $[27,28]$. Here we show that the $\mathrm{N}$-terminal deletion mutant and the double reverse mutant, both of which present the 7 residue deletion near the $\mathrm{N}$-terminus, are unable to inhibit cathepsin B. On the other hand the two point mutations which restore activity to A10 are located distant from the active site loops and therefore must influence activity via an indirect effect.

As depicted in Figure 4A, the first mutation (I30T) is located at the beginning of the $\alpha$-helix where it would be expected to destabilize the hydrophobic cluster formed by residues F50, L53, I30 the aliphatic portion of $\mathrm{R} 34$ and the loop connecting the $\mathrm{N}$-terminus to the $\alpha$ helix (Additional file 2). The second mutation (L97Q) appears yet more significant and perturbs the opposite side of the hydrophobic core formed by L32, F35, A36, V86, F100 and L97 (Figure 4B). We suggest that these mutations would significantly destabilize the hydrophobic contacts which hold the helix against the $\beta$-sheet, thus leading to its complete or partial release. This

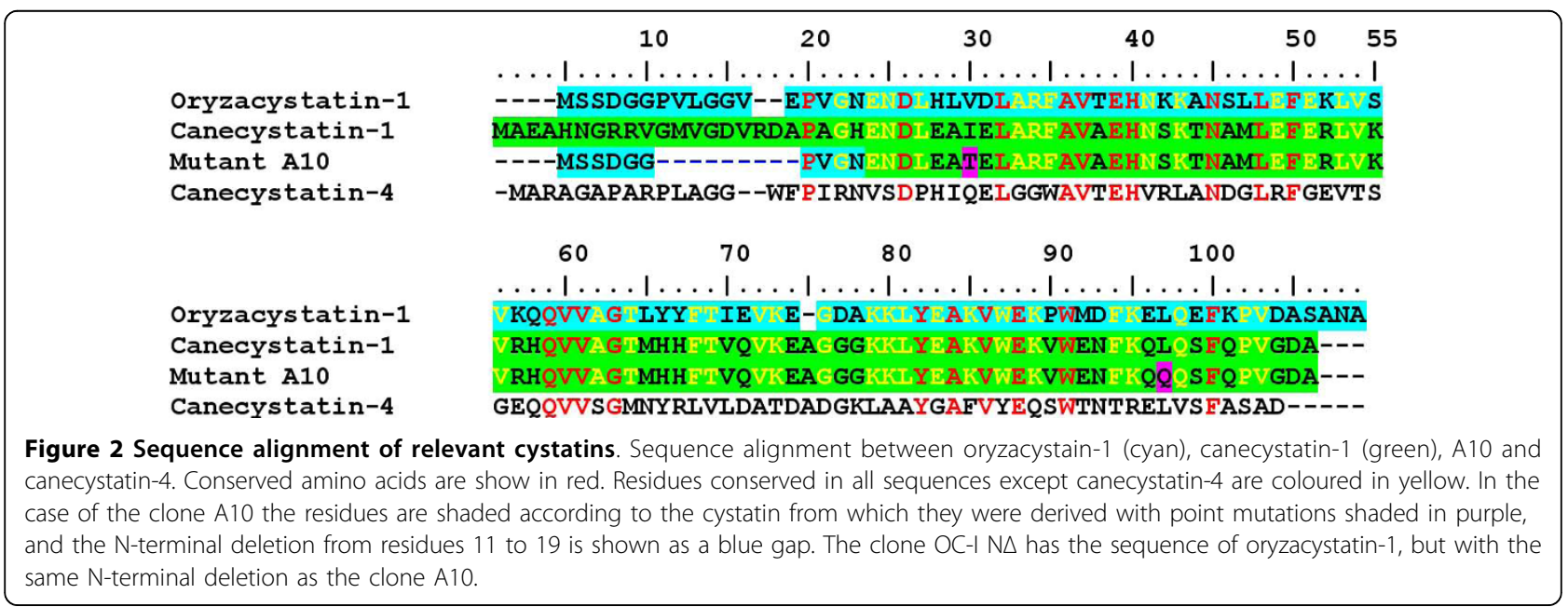




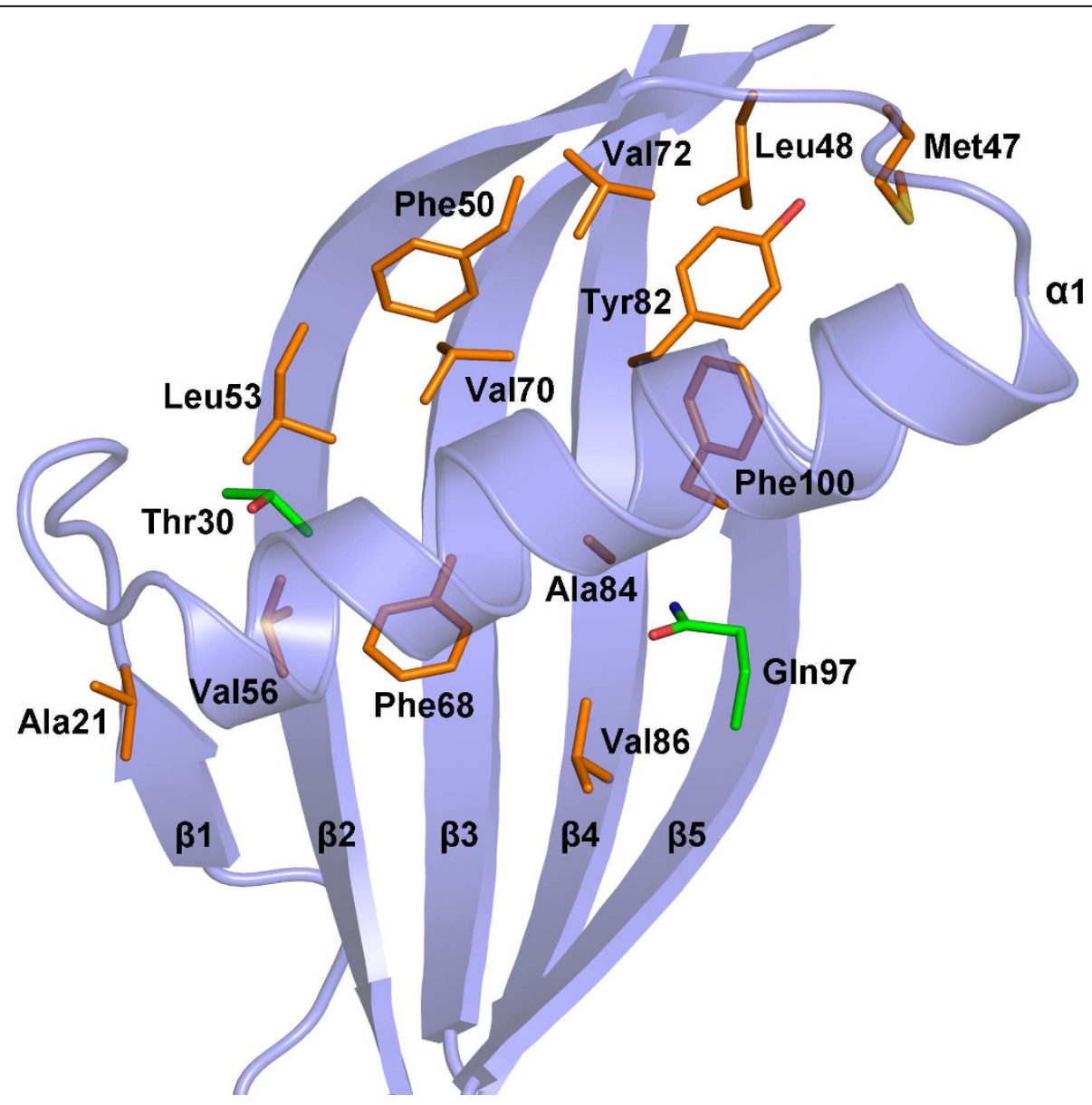

Figure 3 The hydrophobic core residues arising from the anti-parallel $\boldsymbol{\beta}$-sheet of clone A10. The transparent cartoon shows the threedimensional fold of the protein in blue, and the residues participating in the hydrophobic core are colored in orange. Threonine 30 (from the $\alpha$-helix) and glutamine 97 are coloured in green.

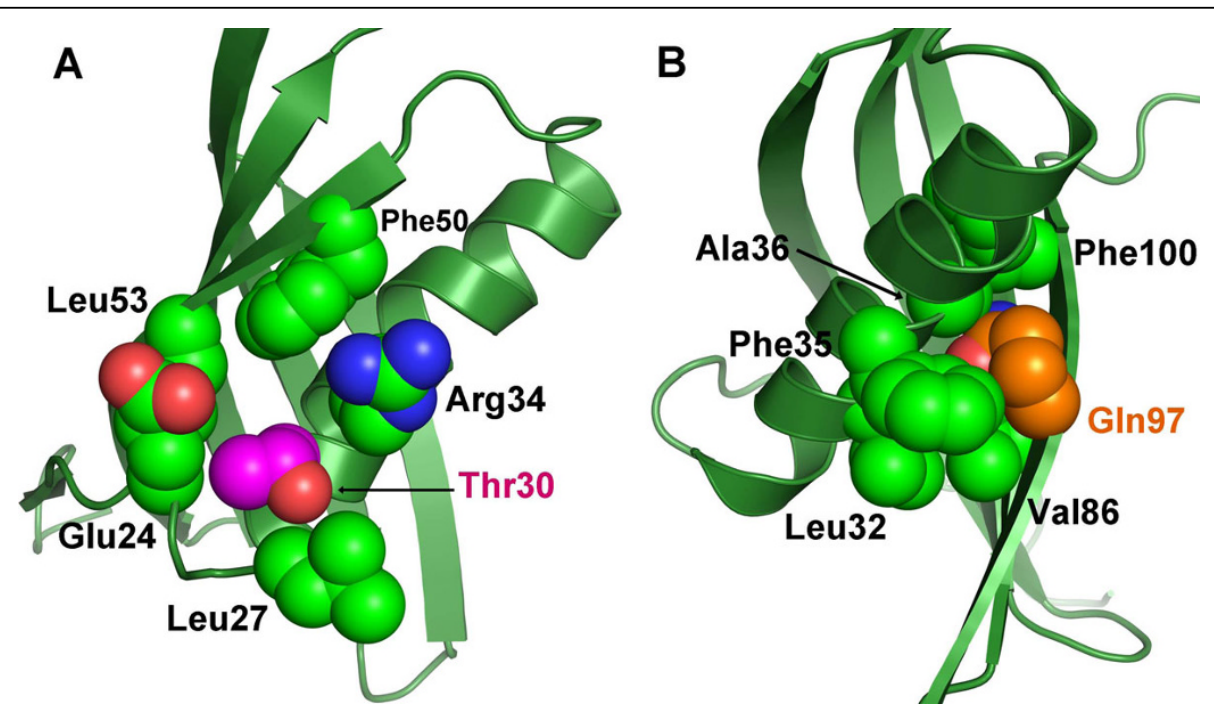

Figure 4 Homology model of clone A10 showing the residues correspondent to the point mutations. Interactions of (A) threonine 30 (magenta) and (B) glutamine 97 (orange). Interacting residues are labeled and shown as spheres. It is likely that the mutations would significantly destabilize the hydrophobic core leading to a conformation different to that shown in the figure. 
release would have the effect of decoupling two components of the inhibitor active site; the $\mathrm{N}$-terminal region on the one hand and the remaining two loops on the other.

The increased flexibility of the $\mathrm{N}$-terminal region in the A10 mutant may allow it to regain its role in the initial binding to the enzyme as the first step in the well established two step mechanism. Alternatively, the uncoupling of the three components of the inhibitor active site may reduce steric hindrance and facilitate direct binding by the QVVAG and VW loops to the catalytic site.

It is noteworthy that the observation of three-dimensional domain swapping within the cystatin family involves exactly the type of structural rearrangement that we are proposing here [29]. This allows cystatins to self assemble into different oligomeric states [30,31] and even form amyloid fibrils [32,33]. Thus it would seem that perturbation of the hydrophobic contacts between these secondary structure elements could readily lead to destabilization of this interface. This hypothesis is further supported by the observation that A10 is much less soluble than the parent molecules and tends to aggregate in inclusion bodies when heterologously expressed (Figure 1), consistent with the exposure or partial exposure of its hydrophobic core. The single reverse mutants show intermediate solubilities, with the T30I mutant (which retains the glutamine at position 97) being the less soluble of the two. However, the inhibition data on these mutants demonstrates that both mutations are necessary for the increased activity of A10 towards cathepsin B.

Although A10 still presents a lower activity towards cathepsin B than other natural cystatins such as its endogenous inhibitor cystatin $C$, the hypothesis raised here presents a rational basis which might be exploitable in the development of tighter binding cathepsin B inhibitors. In this context it is worth mentioning that sugar cane expresses several such inhibitors besides canecystatin-1. For example canecystatin- 4 has been reported to have an affinity comparable to that of cystatin $C[8,25]$. Figure 2 shows that canecystatin- 4 also presents interesting variations to some of the hydrophobic residues at the interface between the helix and the $\beta$-sheet, including a glutamine at position 30 (corresponding to one of the positions mutated in A10) and glycines at positions 47 and 56, which decrease the volume of the hydrophobic core. Furthermore it has been reported that canecystatin4 tends to aggregate more readily than canecystatin-1 [8].

In summary, it is hoped that the methodology and structural insights presented here can be useful in the design of more potent and specific cathepsin inhibitors, as well as contributing to the rationalization of the activity of already characterized cystatins. Specifically, mutations outside the $\mathrm{N}$-terminal region which lead to an altered mobility may be an interesting alternative approach compared with modifying the region itself.

\section{Conclusions}

A combination of experimental approaches including gene shuffling, enzyme assays and reverse mutation has been used to better understand the inhibitory properties of cystatin mutants against Cathepsin B. Molecular modeling of the mutant enzymes suggests that disruption of the hydrophobic core may lead to an increase in the flexibility of the $\mathrm{N}$-terminus, and consequently an increase in inhibitory activity. Such mutations need not affect the inhibitory site directly, but may be observed distant from it and manifest their effects via an uncoupling of its three components as a result of increased protein flexibility.

\section{Additional material}

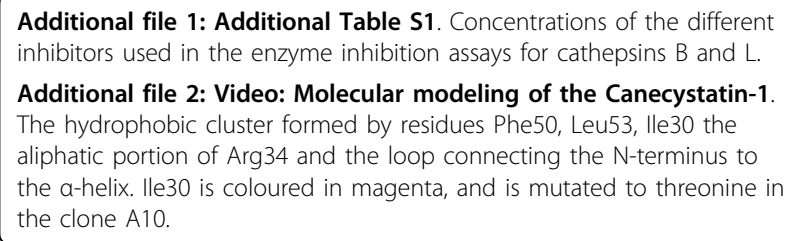

\section{Acknowledgements}

This work was supported by The State of São Paulo Research Foundation (FAPESP, research grant 1998/14138-2 and scholarships to A.S.C. (05/59833-5) and N.F.V. (08/58316-5)). We thank Dr. Stephen J. Benkovic from the Chemistry Department, Pennsylvania State University and Hui Li from the Department of Pathology, University of Washington for their valuable contribution in the DNA shuffling experiments.

\section{Author details}

${ }^{1}$ Center for Structural Molecular Biotechnology, Department of Physics and Informatics, Physics Institute of São Carlos, University of São Paulo, Av.

Trabalhador são-carlense 400, 13560-970, São Carlos-SP, Brazil. ${ }^{2}$ Laboratory of Molecular Biology, Department of Genetic and Evolution, Federal University of São Carlos, Rodovia Washington Luis km 235, CEP 13565-905, São CarlosSP, Brazil.

\section{Authors' contributions}

All authors read and revised the manuscript and approved the final version. MD, ASC and FHS planned and carried out the molecular genetic studies. NFV and RCG planned and performed the structural analysis and wrote the manuscript.

Received: 1 March 2010 Accepted: 30 September 2010

Published: 30 September 2010

\section{References}

1. Mohamed MM, Sloane BF: Cysteine cathepsins: multifunctional enzymes in cancer. Nat Rev Cancer 2006, 6:764-775.

2. Yan S, Sloane BF: Molecular regulation of human cathepsin B: implication in pathologies. Biol Chem 2003, 384:845-854.

3. Hook VY: Unique neuronal functions of cathepsin $L$ and cathepsin $B$ in secretory vesicles: biosynthesis of peptides in neurotransmission and neurodegenerative disease. Biol Chem 2006, 387:1429-1439. 
4. Margis R, Reis EM, Villeret V: Structural and phylogenetic relationships among plant and animal cystatins. Arch Biochem Biophys 1998, 359:24-30

5. Ryan CA: Proteinase inhibitors in plants: genes for improving defenses against insects and pathogens. Annu Rev Phytopathol 1990, 28:425-449.

6. Soares-Costa A, Beltramini LM, Thiemann OH, Henrique-Silva F: A sugarcane cystatin: recombinant expression, purification, and antifungal activity. Biochem Biophys Res Commun 2002, 296:1194-1199.

7. Gianotti A, Rios WM, Soares-Costa A, Nogaroto V, Carmona AK, Oliva ML, Andrade SS, Henrique-Silva F: Recombinant expression, purification, and functional analysis of two novel cystatins from sugarcane (Saccharum officinarum). Protein Expr Purif 2006, 47:483-489.

8. Gianotti A, Sommer CA, Carmona AK, Henrique-Silva F: Inhibitory effect of the sugarcane cystatin CaneCPI-4 on cathepsins $B$ and $L$ and human breast cancer cell invasion. Biol Chem 2008, 389:447-453.

9. Goldemberg J: Ethanol for a sustainable energy future. Science 2007, 315:808-10.

10. Nagata K, Kudo N, Abe K, Arai S, Tanokura M: Three-dimensional solution structure of oryzacystatin-I, a cysteine proteinase inhibitor of the rice Oryza sativa L. japonica. Biochemistry 2000, 39:14753-14760.

11. Stubbs MT, Laber B, Bode W, Huber R, Jerala R, Lenarcic B, Turk V: The refined 2.4 A X-ray crystal structure of recombinant human stefin $B$ in complex with the cysteine proteinase papain: a novel type of proteinase inhibitor interaction. EMBO J 1990, 9:1939-1947.

12. Pavlova A, Bjork I: Grafting of Features of Cystatins $C$ or B into the $\mathrm{N}$ Terminal Region or Second Binding Loop of Cystatin A (Stefin A) Substantially Enhances Inhibition of Cysteine Proteinases. Biochemistry 2003, 42:11326-11333.

13. Novo MTM, Soares-Costa A, de Souza AQL, Figueira ACM, Molina GC, Palacios CA, Kull CR, Monteiro IF, Baldan-Pineda PH, Henrique-Silva F: A Complete Approach for Recombinant Protein Expression Training from Gene Cloning to assessment of protein functionality. Biochemistry and Molecular Biology Education 2002, 33:34-40

14. Sanger F, Nicklens S, Coulson AR: DNA sequencing with chain terminating inhibitors. Proc Natl Acad Science 1977, 74:5463-5467.

15. Laemmli VK: Cleavage of structural protein during the assembly of the head of bacteriophage T4. Nature 1970, 227:680-685.

16. Bradford MM: A rapid and sensitive method for the quantification of microgram quantities of protein utilizing the principle of protein-dye binding. Anal Biochem 1976, 72:248-254.

17. Leatherbarrow RJ: Grafit Version 3.0. Staines, UK: Erithacus Software Ltd 1992.

18. Morrison JF: The slow-binding and slow, tight-binding inhibition of enzyme-catalysed reactions. Trends Biochem Sci 1982, 7:102-105.

19. Knight CG: The Characterization of enzyme inhibition. In Proteinase Inhibitors Edited by: Barrett Salvesen 1986, 23-51.

20. Sali A, Blundell TL: Comparative protein modeling by satisfaction of spatial restraints. J Mol Biol 1993, 234:779-815

21. Shen MY, Sali A: Statistical potential for assessment and prediction of protein structures. Protein Sci 2006, 15:2507-2524.

22. Lüthy $\mathrm{R}$, Bowie JU, Eisenberg D: Assessment of protein models with three-dimensional profiles. Nature 1992, 356:83-85.

23. Vriend G: WHAT IF: a molecular modeling and drug design program. J Mol Graph 1990, 8:52-56.

24. Melo RL, Barbosa Pozzo RC, Alves LC, Perissutti E, Caliendo C, Santagada V, Juliano $L$, Juliano MA: Synthesis and hydrolysis by cathepsin B of fuorogenic substrates with the general structure benzoyl-X-ARG-MCA containing non-natural basic amino acids at position X. Biochimica et Biophysica Acta 2001, 1547:82-94.

25. Nycander M, Estrada S, Mort JS, Abrahamson M, Björk I: Two-step mechanism of inhibition of cathepsin $B$ by cystatin $C$ due to displacement of the proteinase occluding loop. FEBS Lett 1998, 422:61-64.

26. Pavlova A, Krupa JC, Mort JS, Abrahamson M, Björk I: Cystatin inhibition of cathepsin $B$ requires dislocation of the proteinase occluding loop. Demonstration By release of loop anchoring through mutation of his110. FEBS Lett 2000, 487:156-60.

27. Kiggundu A, Goulet MC, Goulet C, Dubuc JF, Rivard D, Benchabane M, Pépin G, van der Vyver C, Kunert K, Michaud D: Modulating the proteinase inhibitory profile of a plant cystatin by single mutations at positively selected amino acid sites. Plant Journal 2006, 48:403-413.
28. Goulet MC, Dallaire C, Vaillancourt LP, Khalf M, Badri AM, Preradov A, Duceppe MO, Goulet C, Cloutier C, Michaud D: Tailoring the Specificity of a Plant Cystatin toward Herbivorous Insect Digestive Cysteine Proteases by Single Mutations at Positively Selected Amino Acid Sites. Plant Physiology 2008, 146:1010-1019.

29. Janowski R, Kozak M, Janowska E, Grzonka Z, Grubb A, Abrahamson M, Jaskolski M: Human cystatin C, an amyloidogenic protein, dimerizes through three-dimensional domain swapping. Nat Struct Biol 2001, 8:316-320.

30. Ohtsubo S, Taiyoji M, Kawase T, Taniguchi M, Saitoh E: Oryzacystatin-II, a cystatin from rice (Oryza sativa L. japonica), is a dimeric protein: possible involvement of the interconversion between dimer and monomer in the regulation of the reactivity of oryzacystatin-II. J Agric Food Chem 2007, 55:1762-6.

31. Jenko Kokalj S, Guncar G, Stern I, Morgan G, Rabzelj S, Kenig M, Staniforth RA, Waltho JP, Zerovnik E, Turk D: Essential role of proline isomerization in stefin B tetramer formation. J Mol Biol 2007, 366:1569-79.

32. Wahlbom M, Wang X, Lindström V, Carlemalm E, Jaskolski M, Grubb A Fibrillogenic oligomers of human cystatin $C$ are formed by propagated domain swapping. J Biol Chem 2007, 282:18318-26.

33. Morgan GJ, Giannini S, Hounslow AM, Craven CJ, Zerovnik E, Turk V, Waltho JP, Staniforth RA: Exclusion of the native alpha-helix from the amyloid fibrils of a mixed alpha/beta protein. J Mol Biol 2008, 375:487-98.

doi:10.1186/1472-6807-10-30

Cite this article as: Valadares et al: Molecular determinants of improved cathepsin B inhibition by new cystatins obtained by DNA shuffling. BMC Structural Biology 2010 10:30.

\section{Submit your next manuscript to BioMed Central and take full advantage of:}

- Convenient online submission

- Thorough peer review

- No space constraints or color figure charges

- Immediate publication on acceptance

- Inclusion in PubMed, CAS, Scopus and Google Scholar

- Research which is freely available for redistribution

Submit your manuscript at www.biomedcentral com/submit
C) Biomed Central 